\title{
Sensitivity of Erysiphe necator to Demethylation Inhibitor Fungicides in Virginia
}

Jeneylyne F. Colcol, Monsanto Company, DeForest, WI 53532; and Lynn Esther Rallos and Anton B. Baudoin, Department of Plant Pathology, Physiology and Weed Science, Virginia Tech, Blacksburg 24061

\begin{abstract}
Colcol, J. F., Rallos, L. E., and Baudoin, A. B. 2012. Sensitivity of Erysiphe necator to demethylation inhibitor fungicides in Virginia. Plant Dis. 96:111-116.

Grape powdery mildew (Erysiphe necator) isolates were collected from 2005 to 2007 from vineyards mostly in Virginia but also some in Maryland, North Carolina, and Pennsylvania. Using a leaf disc assay, the isolates were tested against five demethylation inhibitor (DMI) fungicides. Most isolates exhibited reduced sensitivity to the five DMIs when compared with a sensitive group $(n=12)$ and compared with unexposed populations reported from other areas. The median resistance factor $(\mathrm{RF})$ was highest for tebuconazole $(\mathrm{RF}=399)$ and myclobutanil $(\mathrm{RF}=378)$, followed by triflumizole $(\mathrm{RF}=70)$, triadimefon

$(\mathrm{RF}=62)$, and fenarimol $(\mathrm{RF}=44)$. The sensitive group used as the basis for comparison appears to have been more sensitive than unexposed isolates in New York and California. Our finding that the greatest resistance shift occurred with tebuconazole and myclobutanil contrasts with earlier reports from New York and California, where the greatest resistance shift was observed with triadimefon or triadimenol. Sensitivities to all five DMI fungicides were strongly correlated (pairwise $r$ values of 0.70 to 0.87 ) but our data suggest that some may retain greater utility than others.
\end{abstract}

Powdery mildew (PM), caused by the fungal ascomycete Erysiphe necator Schwein. (formerly Uncinula necator (Schwein.) Burrill), is one of the most important diseases of grape worldwide (14). It can cause severe fruit as well as leaf damage in both humid and dry climates and, because many of the most common and most valuable grape cultivars are very susceptible to PM, it must be controlled by regular application of fungicides. These include older fungicides such as sulfur as well as newer ones such as the demethylation inhibitors (DMIs) and quinone outside inhibitors (QoIs). Although sulfur has been used successfully for well over a century without loss of efficacy, the newer fungicides became popular because they had advantages over the older ones: they provided excellent control at low rates and could be applied at longer intervals. The first DMI approved for use in the U.S. grape market was triadimefon in late 1979, followed by fenarimol in 1989 (21), myclobutanil in 1989, triflumizole in 1995, and tebuconazole in 1999. Tetraconazole received registration in 2009, difenoconazole in 2010, and several additional DMI fungicides have been used in other countries and are currently being tested for possible introduction to the U.S. grape market.

Many of the newer fungicides, especially the benzimidazoles and the QoIs, as well as the sterol DMIs, have suffered from the development of fungicide resistance, which has compromised their use. Reduced efficacy of triadimefon against grape PM was confirmed as early as 1986 in California, followed by other areas such as, New York, Europe, and Ontario $(6,9,13,17,21)$. DMI-exposed PM populations collected from California, New York, and Ontario exhibited significant shifts in the effective concentration providing $50 \%$ inhibition $\left(\mathrm{EC}_{50}\right)$ relative to the DMI-unexposed (sensitive) PM population, and field trials $(6,13)$ confirmed practical DMI resistance. A mutation in the DMI target gene has been documented conferring PM resistance to DMI in European isolates and in one Indian isolate (4).

Corresponding author: J. F. Colcol, E-mail: jfcolcol@vt.edu

Accepted for publication 23 August 2011.

http://dx.doi.org/10.1094/PDIS-12-10-0883

(C) 2012 The American Phytopathological Society
However, in contrast to the benzimidazoles and QoI fungicides, where loss of efficacy is often complete, DMIs often retain partial effectiveness, and resistance to one compound in the group does not necessarily mean equal resistance to other members of the group $(4,6,17,21)$. The mechanisms whereby a fungal isolate may become resistant to one DMI but not another are not well understood and, for practical purposes, it has been considered "generally wise to accept that cross resistance is present between DMI fungicides active against the same fungus" (8). Because the use of a variety of modes of action may minimize resistance shifts for individual compounds, it is important to determine the degree of reduced sensitivity present to members of this group in order to determine what rates and frequencies of use may still be viable. The objective of this study was to determine the sensitivity of grape PM isolates from Virginia and nearby states to sterol DMIs; a preliminary account has been published (3).

\section{Materials and Methods}

The methods for maintaining PM isolates and performing bioassays were adapted from those described by Gubler et al. (9), Erickson and Wilcox (6), Ypema et al. (21), Miller and Gubler (11), and Wong and Wilcox (20).

Leaf material and surface disinfestation. Leaf material for isolation, maintenance, and bioassays was obtained from potted Chardonnay plants grown in a greenhouse with temperatures of 35 to $40^{\circ} \mathrm{C}$ to prevent the development of PM, and long day lengths $(>14 \mathrm{~h})$ to maintain leaf production throughout winter. Young, not yet fully expanded, shiny leaves were collected from the tips of growing shoots and were surface disinfested in $10 \%$ bleach with $0.1 \%$ Tween 20 for 2 min with regular agitation to ensure uniform coverage, rinsed three times in sterile distilled water, and blotted dry between paper towels. One leaf, trimmed if needed to fit into a $60-\mathrm{mm}$ petri plate with approximately $7 \mathrm{ml}$ of $1.5 \%$ water agar (Bacto agar; Difco Laboratories, Detroit), was used in the maintenance of PM isolates while several leaf discs were used in the leaf disc bioassay. Leaves were placed on the agar with the adaxial side facing up.

Collection and maintenance of $\boldsymbol{E}$. necator isolates. Grape leaves infected with PM were collected between 2005 and 2007 from vineyards in Virginia, Maryland, North Carolina, and Pennsylvania (Fig. 1) by either researchers or grape growers. Attempts were made to ensure representation of different geographic re- 
gions. Infected grape leaves were collected from vineyards, sampling as much as possible from separate locations within each vineyard. Leaves from each location were placed separately in Ziploc bags, which were mailed (if collected by growers) or placed in a cooler and transported (if collected by the researchers) immediately to the laboratory.

Upon arrival in the laboratory, samples were immediately examined using a dissecting microscope with side illumination to determine the presence of sporulating E. necator. Leaves with PM infection that appeared to have viable PM conidia were rub inoculated (initial transfer) onto the adaxial surface of grape leaves. The plates were placed in a transparent plastic box and incubated in alternating $12 \mathrm{~h}$ of light and $12 \mathrm{~h}$ of darkness at room temperature for 5 to 7 days.

After incubation, the grape leaves were observed under a dissecting microscope at $\times 40$ magnification to check for PM growth and sporulation. Individual PM isolates were obtained from the initial transfers. A single chain of conidia was picked up using a sterile camel hair attached to a $14.6-\mathrm{cm}$ Pasteur pipette. The camel hair was sterilized by soaking in $70 \%$ ethanol for $10 \mathrm{~min}$, dipped in $95 \%$ ethanol, shaken to remove excess ethanol, and air dried for at least $5 \mathrm{~min}$. The transfer of a single chain of conidia was repeated three consecutive times to ensure the purity of each isolate. Inoculated leaves were incubated as described above. Isolates were transferred after 10 to 14 days or as frequently as necessary. Sterile acupuncture needles were used in the succeeding transfers of the PM isolates because they were more convenient and easier to use than the camel hair. Single-conidial isolates were maintained because we were concerned that the numerous sequential transfers needed to maintain the isolates might lead to selection of nonrepresentative components; for example, resistance frequency in mixed cultures might decline in the absence of fungicide selection pressure.

Biological assay. Fungicides and fungicide concentrations. Sources of technical-grade and formulated fungicides were fenarimol, Gowan Company, Yuma, AZ; myclobutanil, Dow AgroSciences LLC, Indianapolis, IN; tebuconazole and triadimefon, Bayer CropScience, Research Triangle Park, NC; and triflumizole, Chemtura Corporation, Middlebury, CT. Stock solutions of the fungicides were prepared by dissolving the appropriate amount of the technical-grade fungicide into acetone, and were stored in the freezer until use. Serial dilutions were prepared by diluting an aliquot of stock solution in sterile distilled water containing $0.005 \%$ Tween 20 . Fungicide dilutions were prepared the day before use in the bioassay.

The PM isolates were tested against the five fungicides at concentrations of 0 (control), $0.3,1,3$, and $10 \mu \mathrm{g} / \mathrm{ml}$. As a basis for

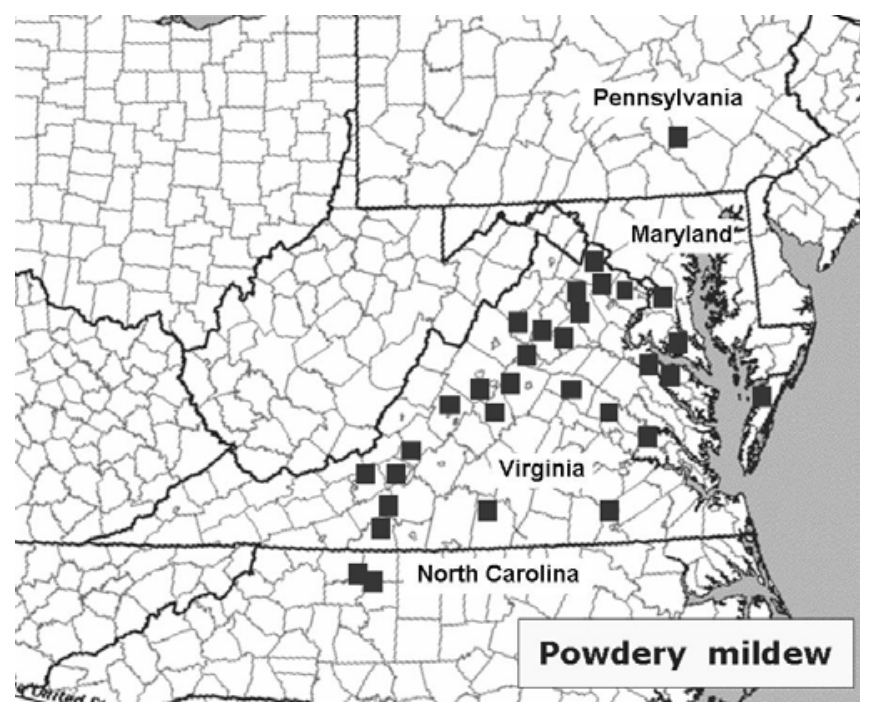

Fig. 1. Collection locations of powdery mildew isolates in Virginia, Maryland, North Carolina, and Pennsylvania. comparison, a fungicide-sensitive group of 12 isolates from two locations that were thought to have had no or very little exposure to single-site fungicides was selected. One location was a new vineyard in Halifax County, VA at least $15 \mathrm{~km}$ from any existing vineyards; the other consisted of a PM population on potted grape plants in Blacksburg, VA, also with no commercial vineyards nearby. The 12 fungicide-sensitive isolates from these two locations did not grow at concentrations of 0.3 through $10 \mu \mathrm{g} / \mathrm{ml}$ of any of the tested fungicides. They were further tested with the same fungicides at $0.001,0.007,0.04,0.15$, and (except for fenarimol) $0.3 \mu \mathrm{g} / \mathrm{ml}$. The $\mathrm{EC}_{50}$ values of this group sensitive to the DMI fungicides were used as the "baseline $\mathrm{EC}_{50}$ " to which the $\mathrm{EC}_{50}$ values of all other PM isolates were compared to determine whether there were significant shifts in their $\mathrm{EC}_{50}$ distribution.

To determine the reproducibility of the bioassay, nine sensitive PM isolates were tested four to five times against all five DMI fungicides at the series of low concentrations listed above.

Preparation of leaf discs for biological assay. Young leaves were surface disinfested as described above and cut into 13-mm leaf discs using a sterile number 9 cork borer. Discs were mixed to randomize them and soaked in fungicide solutions for $1 \mathrm{~h}$ with gentle and continuous shaking on an IKA VIBRAX VXR shaker at $200 \mathrm{rpm}$. They were then blotted dry with a paper towel. In all, 6 to 10 discs were placed in each water agar plate, with the adaxial surface facing up.

PM inoculation and evaluation. Inoculation for the PM sensitivity tests was accomplished using a settling tower after the design of Reifschneider and Boiteux (15) to provide a uniform spore deposit on the leaf discs. Before and after each inoculation, the tower was disinfested by spraying the inside with $95 \%$ ethanol, thoroughly wiped with paper towels, and then allowed to dry for $10 \mathrm{~min}$. Leaves infected with 14- to 21-day-old PM cultures were used as inoculum. Only one PM isolate was used per inoculation event. Conidial deposits were viewed on areas of the agar not covered by leaf tissue; we aimed to achieve approximately 100 conidia per 13$\mathrm{mm}$ disc. Inoculated plates were incubated in a transparent box in the same conditions described for culture maintenance. After 10 days, individual leaf discs were evaluated for disease severity (percent surface area of each leaf disc with PM growth). Evaluation was done with the aid of a dissecting microscope at $\times 40$ magnification. The relative growth of the isolates was determined using the formula: relative growth $=$ (average ratings of leaf discs/average ratings of control) $\times 100 \%$.

In order to estimate the $\mathrm{EC}_{50}$, the relative growth on the treated discs was regressed on the ln-transformed fungicide concentration. Only the linear portions of the response were used to estimate the $\mathrm{EC}_{50}$, which was computed using Microsoft Excel and the formula $\mathrm{EC}_{50}=e^{([50-b] / m]}$ ), from the regression equation $y=m .1 \mathrm{n}$ (concentration $)+b$ (after Miller and Gubler [11] but with $/ m$ rather than $/-m]$.

CYP51 gene sequencing. Single-spored isolates with different sensitivities to the DMIs were grown on young grape leaves for 14 days (as described before) or until sporulation was profuse (maximum of 24 days). The spores were harvested by shaking three sporulating leaves per isolate in sterile distilled water with $0.005 \%$ Tween 20 (STW), collected by membrane filtration, and resuspended in $0.5 \mathrm{ml}$ of STW using a mixer. The spores were frozen at $-50^{\circ} \mathrm{C}$ until DNA extraction. The frozen spore suspension was thawed and centrifuged at $10,000 \mathrm{rpm}$ for $10 \mathrm{~min}$. Three glass beads $(2.5 \mathrm{~mm}$ in diameter; Biospec Products, Inc., Bartlesville, $\mathrm{OK}$ ) were added to the pellet, followed by spore disruption by two cycles of alternate freezing in liquid nitrogen and bead-beating at 4 $\mathrm{m} / \mathrm{s}$ for $30 \mathrm{~s}$ in the FastPrep-24 instrument (MP Biomedicals, Inc., Solon, OH). After a third bead-beating, $300 \mu \mathrm{l}$ of buffer RLT (Qiagen, Inc., Valencia, CA) was immediately added to the tube and mixed well. The suspension was centrifuged at $6,000 \mathrm{rpm}$ for 5 min. DNA extraction was done using the Biosprint 15 DNA Plant Kit (Qiagen, Inc.) according to the manufacturer's instructions.

DNA samples were subjected to polymerase chain reaction (PCR) by one of two methods. In the first method, the primers of 
Délye et al. (4) were used in the following reaction mix: $0.1 \mu \mathrm{M}$ primers $\mathrm{C} 14$ and $\mathrm{C} 14 \mathrm{R}, 1 \times$ Taq $2 \times$ Master Mix (NEB, Ipswich, $\mathrm{MA}$ ), an additional $0.5 \mathrm{mM} \mathrm{MgCl}$, bovine serum albumen at 0.2 $\mathrm{mg} / \mathrm{ml}$, and $35 \mathrm{ng}$ of template DNA in a total reaction volume of 25 $\mu l$. DNA samples from three isolates were subjected to reactions consisting of an initial heating at $94^{\circ} \mathrm{C}$ for $2.5 \mathrm{~min}$; then, 37 cycles of denaturation at $94^{\circ} \mathrm{C}$ for $30 \mathrm{~s}$, annealing at $65^{\circ} \mathrm{C}$ for $1 \mathrm{~min}$, and extension at $72^{\circ} \mathrm{C}$ for $1.5 \mathrm{~min}$; and a final extension at $72^{\circ} \mathrm{C}$ for 1 min. An approximately $1.7-\mathrm{kb}$ band was visualized in $0.8 \%$ agarose in $1 \times$ Tris-acetate-EDTA (TAE) buffer. Additional trials with these primers resulted in two bands that were difficult to separate and remained unresolved. For the second method, Primer 3 software (16) was used to construct another primer set based on the published sequence of Délye et al. (4; GenBank accession number U72657) to amplify the CYP51 from two additional isolates. The primer sequences were $5^{\prime}$-TCA TCT CTT TTC CCA GCC TAT C-3' (FCyp51) and 5'-GTA TTG AGG CGG GTA AAT CG-3' (RCyp51). The PCR reaction consisted of $0.25 \mu \mathrm{M}$ each primer, $1 \times$ Taq $2 \times$ Master Mix (NEB), 10 to $50 \mathrm{ng}$ of template DNA, in a total reaction volume of $25 \mu$ l. The following protocol was used: initial heating at $94^{\circ} \mathrm{C}$ for $2 \mathrm{~min}$; then, 30 cycles of denaturation at $94^{\circ} \mathrm{C}$ for $30 \mathrm{~s}$, annealing at $60^{\circ} \mathrm{C}$ for $30 \mathrm{~s}$, and extension at $72^{\circ} \mathrm{C}$ for $1.5 \mathrm{~min}$; and a final extension at $72^{\circ} \mathrm{C}$ for 5 min. An amplicon of approximately $1.7 \mathrm{~kb}$ in size was also generated with these primers and visualized in $0.8 \%$ agarose in $1 \times$ TAE buffer.

Each PCR product $(5 \mu \mathrm{l})$ was cleaned enzymatically using the following reaction: $1 \mu$ of shrimp alkaline phosphatase (USB, Cleveland, $\mathrm{OH}$ ) at $1 \mathrm{unit} / \mu \mathrm{l}, 0.1 \mu \mathrm{l}$ of exonuclease I (USB) at 10 units $/ \mu \mathrm{l}$, and $5 \mu \mathrm{l}$ of water. The reaction was carried out at $37^{\circ} \mathrm{C}$ for $30 \mathrm{~min}$ then at $65^{\circ} \mathrm{C}$ for $20 \mathrm{~min}$ in the thermal cycler. The clean product was submitted to the University of Chicago Cancer Research Center DNA Sequencing Facility. The sequences were edited and aligned using Lasergene sequence analysis software (DNASTAR, Inc., Madison, WI). The Y136F mutation was confirmed by comparison with published sequences of E. necator CYP51 (GenBank accession numbers U83840.2, EF649776.1, and EF649777.1).

Statistical analyses. There were 140, 141, 136, 145, and 98 isolates tested against fenarimol, myclobutanil, tebuconazole, triadimefon, and triflumizole, respectively. The number of isolates tested for all five DMI fungicides was not the same because some of the isolates died before testing. Isolates used for the reproducibility tests were tested four to five times while, overall, $34 \%$ of all isolates were tested at least twice for fenarimol and myclobutanil, $35 \%$ for tebuconazole, $32 \%$ for triadimefon, and $21 \%$ for triflumizole; the remainder were tested only once.

The range, mean, median, standard deviation, and 95\% confidence intervals of the $\mathrm{EC}_{50}$ values of the sensitive group, and for the remaining group of "exposed" isolates were calculated using JMP 7 (SAS Institute, Cary, NC).
To determine the reproducibility of the bioassay, the mean, variance, coefficient of variation $(\mathrm{CV})$, and $95 \%$ confidence intervals of $\mathrm{EC}_{50}$ values of individual isolates in bioassays that were repeated four or five times were calculated in Microsoft Excel using formulas described by Wong and Wilcox (20).

We wanted to determine whether there was a shift and calculate the magnitude of the shift (resistance factor [RF]) of the average $\mathrm{EC}_{50}$ of fungicide-exposed PM isolates compared with the average $\mathrm{EC}_{50}$ of the sensitive group. The frequency distributions of all PM isolates and the sensitive group were not log normally distributed but somewhat skewed. Thus, the Wilcoxon/Kruskal-Wallis nonparametric test was performed using JMP 7 to determine whether the frequency distributions of DMI sensitivity of the exposed PM isolates and the sensitive group were significantly different.

\section{Results and Discussion}

Bioassays and isolates tested. The $\mathrm{CV}$ of the $\mathrm{EC}_{50}$ of individual isolates ranged from 10 to $64 \%$, with a mean of 26 to $37 \%$ for the different fungicides (Table 1), which shows only moderate variation in the repeated bioassays, indicating that the bioassays were reproducible. The computed CVs for the repeated PM assays for myclobutanil and triadimefon were similar to the values obtained by Erickson and Wilcox (6) (who used triadimenol) and Wong and Wilcox (20).

The number of isolates tested against each fungicide (Materials and Methods; Fig. 2) varied because some isolates died before they could be tested against all five DMIs, and triflumizole was not included in the early tests. PM isolates from 31 locations were obtained and tested; 17 locations were represented by fewer than 5 isolates, 10 locations represented by 5 to 9 isolates, and 4 represented by 10 to 14 isolates.

Sensitive populations. The mean and median $\mathrm{EC}_{50}$ of the 12 isolates in the sensitive group from two unexposed locations are shown in Table 2 and Figure 2. The lowest median $\mathrm{EC}_{50}$ values were those of myclobutanil and fenarimol, followed by tebuconazole, triflumizole, and triadimefon. The number of isolates in our unexposed group was small but the relative sensitivity is consistent with the observations by Erickson and Wilcox (6), Gubler et al. (9), and Ypema et al. (21), who also found that $\mathrm{EC}_{50}$ values for triadimefon or triadimenol were higher than those for fenarimol and myclobutanil in PM isolates not exposed to DMI fungicides, indicating differences in inherent activity. One might consider that comparison on a per-molecule basis has greater validity but the compound with the heaviest molecule (triflumizole, 345.75 ) has a molecular weight only $20 \%$ greater than the lightest (myclobutanil, 288.78); therefore, this has little effect on the comparison. Tebuconazole and triflumizole data were not included in these earlier studies because they did not become registered for use on grape until later; we have not found published baseline data on the sensitivity of E. necator to these compounds.

Table 1. Reproducibility of the biosassays of Erysiphe necator $(n=9)$ against fenarimol, myclobutanil, tebuconazole, triadimefon, and triflumizole ${ }^{\text {a }}$

\begin{tabular}{|c|c|c|c|c|c|c|c|c|c|c|c|c|c|c|c|}
\hline \multirow[b]{2}{*}{ Isolate } & \multicolumn{3}{|c|}{ Fenarimol } & \multicolumn{3}{|c|}{ Myclobutanil } & \multicolumn{3}{|c|}{ Tebuconazole } & \multicolumn{3}{|c|}{ Triadimefon } & \multicolumn{3}{|c|}{ Triflumizole } \\
\hline & Mean & $\begin{array}{c}\text { CV } \\
(\%)\end{array}$ & $\begin{array}{c}95 \% \\
\text { CI }\end{array}$ & Mean & $\begin{array}{l}\text { CV } \\
(\%)\end{array}$ & $\begin{array}{c}95 \% \\
\text { CI }\end{array}$ & Mean & $\begin{array}{c}\text { CV } \\
(\%)\end{array}$ & $\begin{array}{c}95 \% \\
\text { CI }\end{array}$ & Mean & $\begin{array}{l}\text { CV } \\
(\%)\end{array}$ & $\begin{array}{c}95 \% \\
\text { CI }\end{array}$ & Mean & $\begin{array}{l}\text { CV } \\
(\%)\end{array}$ & $\begin{array}{c}95 \% \\
\text { CI }\end{array}$ \\
\hline BL-P1 & 0.005 & 12 & $0.005-0.007$ & 0.011 & 12 & $0.010-0.014$ & 0.020 & 38 & $0.013-0.096$ & 0.014 & 32 & $0.010-0.035$ & 0.016 & 31 & $0.011-0.041$ \\
\hline BL-P4 & 0.013 & 50 & $0.008-0.074$ & 0.023 & 42 & $0.016-0.068$ & 0.031 & 27 & $0.022-0.060$ & 0.020 & 23 & $0.015-0.037$ & 0.025 & 37 & $0.017-0.062$ \\
\hline MV-P1 & 0.014 & 26 & $0.010-0.028$ & 0.007 & 21 & $0.005-0.011$ & 0.009 & 10 & $0.008-0.011$ & 0.017 & 33 & $0.012-0.037$ & 0.013 & 25 & $0.010-0.024$ \\
\hline MV-P2 & 0.004 & 15 & $0.004-0.008$ & 0.005 & 28 & $0.004-0.009$ & 0.001 & 43 & $0.0004-0.004$ & 0.028 & 32 & $0.020-0.076$ & 0.018 & 25 & $0.014-0.030$ \\
\hline MV-P5 & 0.007 & 26 & $0.005-0.014$ & 0.006 & 25 & $0.004-0.013$ & 0.009 & 13 & $0.007-0.011$ & 0.019 & 57 & $0.012-0.108$ & 0.007 & 19 & $0.005-0.010$ \\
\hline MV-P8 & 0.012 & 40 & $0.008-0.036$ & 0.001 & 16 & $0.0005-0.001$ & 0.005 & 51 & $0.004-0.705$ & 0.015 & 29 & $0.011-0.041$ & 0.013 & 44 & $0.008-0.101$ \\
\hline MV-P9 & 0.002 & 37 & $0.001-0.012$ & 0.005 & 30 & $0.003-0.010$ & 0.004 & 34 & $0.003-0.011$ & 0.035 & 29 & $0.025-0.077$ & 0.007 & 20 & $0.005-0.011$ \\
\hline MV-P10 & 0.004 & 39 & $0.003-0.017$ & 0.004 & 36 & $0.003-0.011$ & 0.006 & 27 & $0.006-0.012$ & 0.005 & 28 & $0.003-0.011$ & 0.008 & 21 & $0.006-0.013$ \\
\hline PB-P1 & 0.006 & 25 & $0.004-0.009$ & 0.013 & 34 & $0.009-0.038$ & 0.032 & 31 & $0.023-0.066$ & 0.037 & 55 & $0.025-32.57^{b}$ & 0.086 & 13 & $0.072-0.112$ \\
\hline Mean & 0.008 & 30 & $\ldots$ & 0.008 & 27 & $\ldots$ & 0.013 & 31 & $\ldots$ & 0.021 & 36 & & 0.021 & 26 & $\ldots$ \\
\hline
\end{tabular}

${ }^{\text {a }}$ Mean $(\mu \mathrm{g} / \mathrm{ml}), \mathrm{CV}=$ coefficient of variation and $\mathrm{CI}=$ confidence interval

${ }^{\mathrm{b}}$ High upper limit due to one anomalously low value that made the variance large. Individual values for MV-P8/tebuconazole were: $0.0097,0.0081,0.0076$, 0.0094 , and 0.0008 , and for PB-P1/triadimefon: 0.0635, 0.0508, 0.0730, 0.0038, and 0.0743. 
Although the rankings of the sensitivities to different compounds were similar, our sensitive group overall was more sensitive than unexposed populations in New York and California $(6,9)$ and sensitive isolates tested in France (4). The median $\mathrm{EC}_{50}$ values of two New York PM populations without prior exposure to DMIs were $0.03,0.03$, and $0.06 \mu \mathrm{g} / \mathrm{ml}$ for fenarimol, myclobutanil, and
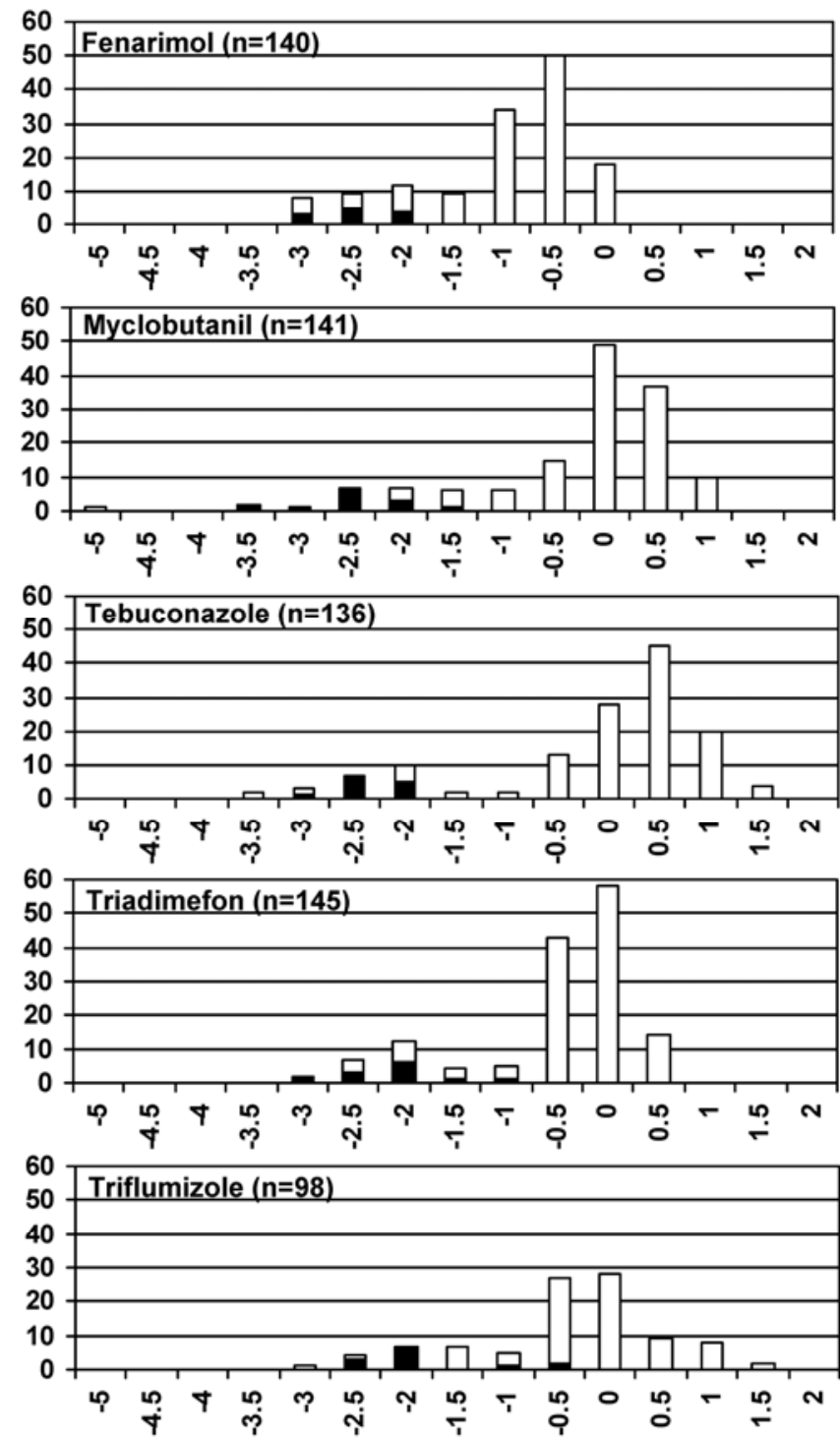

Fig. 2. Frequency distribution of the $\log _{10}$ effective concentration providing $50 \%$ inhibition of the sensitive group and all Mid-Atlantic United States powdery mildew (PM) isolates of Erysiphe necator to fenarimol, myclobutanil, tebuconazole, triadimefon, and triflumizole. Dark bars represent a sensitive group (namely, isolates from two sites that had very little or no exposure to single-site fungicides) and white bars represent counts for all PM isolates. triadimefon, respectively (6). These values were 3.3 to 5 times higher than our values shown in Table 2. Part of these differences may be due to differences in the methods used in the bioassay. Erickson and Wilcox (6) inoculated each individual leaf disc in its center with a conidium and measured the colony diameter. In our tests, we inoculated all leaf discs in an inoculation tower, which deposited PM conidia at random, and visually estimated percent coverage of each leaf disc. A $50 \%$ reduction in diameter of a colony would, by simple geometry, coincide with a $75 \%$ reduction in surface area covered by the colony, indicating that $\mathrm{EC}_{50}$ values based on surface area will be somewhat lower than those based on diameters.

Compared with our sensitive group, the mean $\mathrm{EC}_{50}$ values of an unexposed PM population in California (9) were considerably higher: 44-fold higher $(1.40 \mu \mathrm{g} / \mathrm{ml})$ for triadimefon, 6-fold higher $(0.15 \mu \mathrm{g} / \mathrm{ml})$ for myclobutanil, and 14-fold higher $(0.13 \mu \mathrm{g} / \mathrm{ml})$ for fenarimol. Sensitive isolates tested by Délye et al. (4) had a mean $\mathrm{EC}_{50}$ for triadimenol of $0.85 \mu \mathrm{M}$, or $0.25 \mu \mathrm{g} / \mathrm{ml}$, eight times higher than our mean. The California and French $\mathrm{EC}_{50}$ values were based on PM surface area estimates, as were ours. Gubler et al. (9) and, in most of the tests, Ypema et al. (21) used heterogeneous E. necator subcultures in their bioassay to increase the probability of detecting isolates with the highest level of resistance, whereas we assayed single-conidial E. necator isolates, as did Erickson and Wilcox (6). Ypema et al. (21) found only small differences between the response of heterogeneous subcultures and monoconidial isolates; the difference was statistically significant for fenarimol but not for triadimefon and myclobutanil. Another difference in methods is that Gubler et al. (9) and Ypema et al. (21) sprayed leaf disks with fungicide suspensions and allowed the deposits to dry, whereas Erickson and Wilcox (6) and our group soaked leaf disks in fungicide suspensions for $30 \mathrm{~min}(6)$ or $1 \mathrm{~h}$ (this study). Alternatively or additionally, it is possible that the higher $\mathrm{EC}_{50}$ of the unexposed PM population in California is, indeed, a reflection of its greater fungicide tolerance at the time of sampling compared with our nonexposed isolates.

DMI-exposed populations. All isolates that were not in our unexposed, sensitive group were considered "exposed"; they were from commercial or experimental vineyards with conventional spray programs. Spray records for 2 to 5 years before sample collection were obtained for 20 sites (representing 129 isolates) from which samples were obtained but were unavailable for 11 others (28 isolates). Tebuconazole and myclobutanil were the most commonly used DMIs, with 47 and 45\%, respectively, of 190 DMI applications reported, followed by fenarimol (13 applications at five sites) and triflumizole ( 2 applications at two sites). Triadimefon was not used by the growers who provided information in the years for which records were available. The highest average number of DMI applications per year for a vineyard was 4.6, the median number for exposed vineyards was 3.0, and the average 2.7.

The mean and median $\mathrm{EC}_{50}$ values of our exposed PM collection for each of the five DMI fungicides were considerably higher than those of the sensitive group (Table 2; Fig. 2). For each fungicide, the differences of the mean and median of the sensitive group with those of the exposed PM collection were highly significant at $P>$

Table 2. Comparison of mean and median effective concentration providing 50\% inhibition $\left(\mathrm{EC}_{50}\right)(\mu \mathrm{g} / \mathrm{ml})$, resistance factors of the "exposed" Erysiphe necator collection, and relation to maximum label rates for five demethylation inhibitor fungicides

\begin{tabular}{|c|c|c|c|c|c|c|}
\hline Parameters & Statistic & Fenarimol & Myclobutanil & Tebuconazole & Triadimefon & Triflumizole \\
\hline \multirow[t]{2}{*}{$\mathrm{EC}_{50}$ of the sensitive group } & Mean & 0.009 & 0.025 & 0.089 & 0.032 & 0.116 \\
\hline & Median & 0.008 & 0.006 & 0.009 & 0.018 & 0.017 \\
\hline \multirow[t]{2}{*}{$\mathrm{EC}_{50}$ of exposed populations } & Mean & 0.48 & 3.59 & 6.65 & 1.43 & 3.62 \\
\hline & Median & 0.35 & 2.27 & 3.59 & 1.12 & 1.19 \\
\hline \multirow[t]{2}{*}{ Resistance factor } & Mean & 53 & 144 & 75 & 45 & 31 \\
\hline & Median & 44 & 378 & 399 & 62 & 70 \\
\hline Maximum label rate $(\mu \mathrm{g} \text { a.i. } / \mathrm{ml})^{\mathrm{a}}$ & $\ldots$ & 56 & 150 & 135 & 225 & 300 \\
\hline $\begin{array}{l}\mathrm{EC}_{50} \text { of exposed collection as percentage } \\
\text { of maximum label rate }\end{array}$ & Median & 0.63 & 1.51 & 2.66 & 0.50 & 0.40 \\
\hline
\end{tabular}

a As a concentration, based on a spray volume of 945 liters/ha (100 gallons/acre). 
0.0001 in the Wilcoxon/Kruskal-Wallis nonparametric test. Tebuconazole had the highest median $\mathrm{EC}_{50}$ followed by, in decreasing order, myclobutanil, triflumizole, triadimefon, and fenarimol (Table 2). When comparing the median $\mathrm{EC}_{50}$ values of these five DMI fungicides, one should take into account that they have different intrinsic activities, as reflected in $\mathrm{EC}_{50}$ values of the sensitive group and of unexposed populations elsewhere. We expect that such differences will also be reflected in their labeled field application rates, although other factors, such as chemical stability, tissue penetration and translocation, and weathering characteristics will influence label rates as well. $\mathrm{EC}_{50}$ expressed as a $\mathrm{RF}$ compared with the sensitive group and as a percentage of the maximum label rate is shown in Table 2. Label rates in the United States are usually expressed as amount of product per acre; we have calculated concentrations assuming a water volume of 945 liters/ha (100 gallons/acre), and the highest rate if a range is given. Tebuconazole and myclobutanil had a greater RF than the other three fungicides, and their tolerance was also highest when expressed as a percentage of the label rate. Although our isolates did not appear highly sensitive to triflumizole from the $\mathrm{EC}_{50}$ expressed as a concentration, when expressed as a RF or in relation to the maximum label rate, the resistance shift for triflumizole was similar to that for fenarimol and triadimefon and less than for tebuconazole and myclobutanil.

The median $\mathrm{EC}_{50}$ of our exposed PM collection (Table 2) for fenarimol was 5-fold higher than the $\mathrm{EC}_{50}$ of the DMI-exposed New York PM isolates (6) (New York value $0.07 \mu \mathrm{g} / \mathrm{ml}$ ) and, for myclobutanil, 10-fold higher (New York value $0.23 \mu \mathrm{g} / \mathrm{ml}$ ). Interestingly, the median $\mathrm{EC}_{50}$ of our exposed PM collection for triadimefon was only $59 \%$ of the median $\mathrm{EC}_{50}$ of $1.9 \mu \mathrm{g} / \mathrm{ml}$ for triadimenol of the exposed New York population (6).

Our sensitive group was small and appeared more sensitive in comparison with other reports; therefore, we also calculated RFs of our exposed PM collection relative to unexposed New York isolates of 10 years earlier; these median RFs were 12 for fenarimol, 76 for myclobutanil, and 19 for triadimefon (compared with the unexposed New York triadimenol value). Equivalent median RFs for DMI-exposed New York isolates (6) were 2 for fenarimol, 8 for myclobutanil, and 32 for triadimenol.

DMI-exposed PM populations from different regions in California differed in sensitivity; the highest mean $\mathrm{EC}_{50}(16.48 \mu \mathrm{g} / \mathrm{ml})$ for triadimefon was from the PM population collected from the central coast and the lowest mean $\mathrm{EC}_{50}$ from the north coast $(4.33 \mu \mathrm{g} / \mathrm{ml})$ (9). These values are 12- and 3-fold higher, respectively, than the mean $\mathrm{EC}_{50}$ of $1.43 \mu \mathrm{g} / \mathrm{ml}$ of our exposed PM collection for triadimefon. However, the mean $\mathrm{EC}_{50}$ values of our exposed PM collection for myclobutanil $(3.59 \mu \mathrm{g} / \mathrm{ml})$ and fenarimol $(0.48$ $\mu \mathrm{g} / \mathrm{ml}$ ) were similar to the mean $\mathrm{EC}_{50}$ values of isolates from the central coast of California for myclobutanil $(2.83 \mu \mathrm{g} / \mathrm{ml})$ and fenarimol $(0.44 \mu \mathrm{g} / \mathrm{ml})(9)$.

Steva and Clerjeau (17) described a few E. necator isolates from France and Portugal. These authors evaluated surface area and degree of sporulation, and reported mean $\mathrm{EC}_{50}$ values for two sensitive isolates of $0.16 \mu \mathrm{g} / \mathrm{ml}$ for triadimenol, $0.25 \mu \mathrm{g} / \mathrm{ml}$ for triadimefon, $0.06 \mu \mathrm{g} / \mathrm{ml}$ for myclobutanil, and individual values of 1.77 (which is high, compared with all other reports) and 0.22 $\mu \mathrm{g} / \mathrm{ml}$ for fenarimol (17). Délye et al (4) did not report mean $\mathrm{EC}_{50}$ values for their resistant isolates but they considered RF values between 5 and $10(1.26$ to $2.51 \mu \mathrm{g} / \mathrm{ml})$ to be moderately resistant in their collection, and RF values over 10 to be highly resistant.

Due to the incomplete nature of spray history information and the small number of isolates from many of the individual locations, it was difficult to discern relationships between $\mathrm{EC}_{50}$ and spray history. For isolates from three vineyards (each represented by at least five isolates) that had had exclusively tebuconazole applied, the mean $\mathrm{EC}_{50}$ for tebuconazole was $6.19(n=24)$ and for myclobutanil was $2.68(n=21)$. Isolates from three vineyards with only myclobutanil applied had a median $\mathrm{EC}_{50}$ for tebuconazole of $8.62(n=19)$ and for myclobutanil of $3.79(n=20)$, almost the same ratio.
$\mathbf{E C}_{\mathbf{5 0}}$ correlations. There were 82 E. necator isolates that had complete $\mathrm{EC}_{50}$ data for all five DMIs used in the bioassays. A pairwise analysis of the $\log _{10} \mathrm{EC}_{50}$ of these 82 isolates found high and statistically significant positive correlations $(r>0.7)$ for all fungicide pairs (Table 3 ). This indicates that the sensitivities of the $E$. necator population to the DMI fungicides are related to each other. Positive correlations between grape PM sensitivities to different DMIs have been documented previously $(6,9,21)$ and are expected based on the fact that all DMIs affect the same fungal target site. Cross resistance has been defined as the "reaction to two or more toxicants mediated by the same genetic factor" (5). Exposure to one fungicide in a group may then lead to selection for resistance to all group members. In an example given by Ypema et al. (21), a decline was found in sensitivity of grape PM to three DMIs in the course of a season, even though only triadimefon was applied.

The lower $\mathrm{EC}_{50}$ values for triadimefon compared with tebuconazole and myclobutanil were unanticipated because previous reports from California and New York suggested that triadimefon had the greatest resistance problem among the DMIs. Miller and Gubler (11) reported that triadimefon resistance in California in 2002 was still high (mean $\mathrm{EC}_{50}$ of $8.8 \mu \mathrm{g} / \mathrm{ml}$ ), even after many years of little use. We do not have PM sensitivity data from earlier decades in Virginia. Triadimefon was once commonly used on Virginia grapes and perhaps triadimefon tolerance may have been higher than it is now. Data from the National Agricultural Statistics Service (12) for New York, Pennsylvania, and Michigan and from our own survey suggest that (i) the use of triadimefon on grape in the eastern United States has greatly declined since the mid 1990s, (ii) triflumizole has probably not been used much in any year on eastern U.S. grapes, and (iii) fenarimol may have seen moderate, sustained use over the years. Myclobutanil and tebuconazole have been considered the DMI fungicides of choice, due to their excellent activity against black rot and lesser concern about PM tolerance than with triadimefon (2). The New York and California isolates were collected 10 to 15 years before ours. We suspect that those years provided more time for a higher level of resistance to develop, especially for fungicides that were then new but have been commonly used since, such as myclobutanil and, more recently, tebuconazole, and that triadimefon resistance may have declined.

DMIs were more important for PM control in the 1980s and 1990s but, since the late 1990s, some of the load has been carried by the QoI fungicides, especially perhaps in the eastern United States because QoIs provide control of a greater number of important grape diseases. However, with the advent of QoI resistance $(1,18)$ and the registration of additional DMIs, some movement back to DMIs may be expected.

The correlations we observed in our study were only partial, and some of our isolates had a high $\mathrm{EC}_{50}$ to one fungicide and much lower values for others. The partial nature of positive correlations was also noted by Erickson and Wilcox (6) and Steva and Clerjeau (17): an isolate resistant to one DMI does not always have increased resistance to another. Two triadimenol-resistant isolates had RFs of 15.9 and 30.1 for triadimenol, 3.7 and 99.2 for triadimefon, 2.9 and 6.9 for myclobutanil, 6.2 and 11.9 for flusilazole, but values that did not differ substantially from 1 for 10 other

Table 3. $R$ values summarizing the correlations of the $\log _{10}$ effective concentration providing $50 \%$ inhibition $\left(\mathrm{EC}_{50}\right)$ of 82 Erysiphe necator isolates for fenarimol, myclobutanil, tebuconazole, triadimefon, and triflumizole ${ }^{\mathrm{a}}$

\begin{tabular}{lcccc}
\hline Fungicide & Fenarimol & Myclobutanil & Tebuconazole & Triadimefon \\
\hline Fenarimol & $\ldots$ & $\ldots$ & $\ldots$ & $\ldots$ \\
Myclobutanil & 0.80 & $\ldots$ & $\ldots$ & $\ldots$ \\
Tebuconazole & 0.82 & 0.85 & $\ldots$ & $\ldots$ \\
Triadimefon & 0.87 & 0.85 & 0.83 & $\ldots$ \\
Triflumizole & 0.70 & 0.82 & 0.75 & 0.75 \\
\hline \multicolumn{2}{l}{ a Correlations were estimated by restricted or residual maximum likelihood }
\end{tabular}

Correlations were estimated by restricted or residual maximum likelihood method (REML; JMP 8; SAS Institute). 
DMI fungicides (17). Partial DMI cross-resistance has also been reported for other pathogens, such as Ustilago avenae (10). We speculate that there may be two types of mutations or mechanisms conferring DMI resistance: namely, fungicide-specific and groupspecific mechanisms. Fungicide-specific mechanisms are those that confer resistance to one or several but not all DMI fungicides, whereas group-specific mechanisms confer resistance to all DMI fungicides. In our study, we speculate that the partial cross resistance exhibited by our DMI-resistant isolates could be explained by a mixture of fungicide-specific and group-specific mechanisms in the population. Fraaije et al. (7) described an example of a fungicide-specific mutation, I381V in Mycosphaerella graminicola, which was positively selected by tebuconazole and difenoconazole treatment but appeared to be negatively selected by prochloraz. Partial sequencing of five isolates in our collection revealed a section identical with the E. necator CYP51 gene reported previously in Europe (4). This section contained the point mutation conferring the amino acid change from tyrosine to phenylalanine at position $136(\mathrm{Y} 136 \mathrm{~F})(4)$. This mutation was absent in all three sensitive isolates $\left(\mathrm{EC}_{50}<0.1\right.$ to DMIs tested) but occurred in both isolates with reduced sensitivity to DMIs (myclobutanil $\mathrm{EC}_{50}=5$ to $7 \mu \mathrm{g} / \mathrm{ml}$, tebuconazole $\mathrm{EC}_{50}=4$ to $8 \mu \mathrm{g} / \mathrm{ml}$, and triadimefon $\mathrm{EC}_{50}=2$ to $5 \mu \mathrm{g} / \mathrm{ml}$ ), resistance levels that are consistent with those found by Délye et al. (4) in triadimenol-resistant E. necator possessing the Y136F mutation. Experiments are under way to obtain more DNA sequence data to correlate this mutation or other nucleotide changes to our observed resistance phenotypes.

Relevance to field control. An important question is to what extent this shift in the $\mathrm{EC}_{50}$ of $\mathrm{PM}$ isolates translates into practical resistance in the field. Erickson and Wilcox (6) observed that a 30fold difference in the median $\mathrm{EC}_{50}$ for triadimenol between the exposed and unexposed PM population in New York resulted in less than 50\% control of PM, whereas the exposed PM population with 2- and 8-fold increase in the median $\mathrm{EC}_{50}$ for fenarimol and myclobutanil, respectively was still controlled by labeled rates of both fungicides. The RFs that we calculated were all at the high end of this range (Table 2). However, the median $\mathrm{EC}_{50}$ for fenarimol, myclobutanil, and triadimefon of our sensitive group that was used to calculate the RF of exposed PM isolates was 3.8-, 5-, and 3.3-fold lower for fenarimol, myclobutanil, and triadimefon, respectively, than the median $\mathrm{EC}_{50}$ of the unexposed (sensitive) New York PM isolates; this may be due, in part, to the limited number of sensitive isolates included $(n=12)$.

The results of laboratory bioassays may not be readily translated into predicted efficacy of individual fungicides in the field. Our results suggest that, among the five DMI fungicides, triflumizole, fenarimol, and triadimefon might be expected to provide the best control of grape PM in the vineyards where our isolates were collected. However, the registration of triadimefon for use on grape has recently been discontinued. Our PM isolates had only modest reductions of sensitivity to fenarimol. Because the shift is modest considering that fenarimol has been used against PM for almost 20 years now (but in moderate sustained use), it is possible that grape PM for unknown reasons may have difficulty developing a higher level of resistance to fenarimol, or that fenarimol resistance may have a greater fitness penalty. However, field trials in several vineyards with DMI-resistant populations have not confirmed that fenarimol performed better than tebuconazole (19) (A. B. Baudoin, W. G. Giese, and L. E. Rallos, unpublished data).

More information is needed on the practical level of PM control that DMI fungicides can still provide in vineyards with reduced sensitivity. The bioassay tests to determine DMI sensitivity of PM are labor intensive and impractical for growers. Another complicating factor is that our recent data suggest that some of the singlespored isolates, maintained as described, may have gradually lost some of their earlier resistance to the DMI fungicides. Occasional loss of an isolate to contamination is to be expected but appears unlikely to be solely responsible. If further research confirms this, it will be an additional factor that needs to be taken into account when trying to relate bioassay results to field performance. It may be possible to develop a practical way of testing PM sensitivity to DMIs by spraying potted grape plants with various rates of DMI fungicides, placing them near vineyards, and evaluating them for PM growth.

\section{Acknowledgments}

We thank the Virginia Wine Board, Viticulture Consortium-East, and the Virginia Agricultural Council for their financial support; Y. (Daisy) Chung, Z Miller, J. H. (Esther) Kuen, and J. Lewis for their capable technical assistance in performing bioassays; D. Schmale and T. Wolf for their valuable suggestions and comments; and the grape growers and others who provided disease samples.

\section{Literature Cited}

1. Baudoin, A., Olaya, G., Delmotte, F., Colcol, J. F., and Sierotzki, H. 2008 QoI resistance of Plasmopara viticola and Erysiphe necator in the midAtlantic United States. Plant Health Progress. Online publication. doi:10.1094/PHP-2008-0211-02-RS.

2. Bordelon, B., Ellis, M., and Foster, R., eds. 2006. Midwest Commercial Small Fruit and Grape Spray Guide 2006. Coop. Ext. Serv. 12 Midwest. States.

3. Colcol, J. F., and Baudoin, A. B. 2008. Fungicide resistance of Erysiphe necator in the U.S. Mid-Atlantic region. (Abstr.) Phytopathology 98:S40.

4. Délye, C., Laigret, F., and Corio-Costet, M-F. 1997. A mutation in the $14 \alpha$ demethylase gene of Uncinula necator that correlates with resistance to a sterol biosynthesis inhibitor. Appl. Environ. Microbiol. 63:2966-2970.

5. EPPO. 1988. Fungicide resistance: definitions and use of terms. EPPO Bull. 18:569-574.

6. Erickson, E. O., and Wilcox, W. F. 1997. Distributions of sensitivities to three sterol demethylation inhibitor fungicides among populations of $U n-$ cinula necator sensitive and resistant to triadimefon. Phytopathology 87:784-791.

7. Fraaije, B. A., Cools, H. J., Kim, S.-H., Motteram, J., Clark, W. S., and Lucas, J. A. 2007. A novel substitution I38V in the sterol $14 \alpha$-demethylase (CYP51) of Mycosphaerella graminicola is differently selected by azole fungicides. Mol. Plant Pathol. 8:245-254.

8. FRAC. 2010. FRAC Code List: Fungicides sorted by mode of action (including FRAC Code numbering). http://www.frac.info/frac/publication/ anhang/FRAC_Code_List_2010.pdf.

9. Gubler, W. D., Ypema, H. L., Ouimette, D. G., and Bettiga, L. J. 1996 Occurrence of resistance in Uncinula necator to triadimefon, myclobutanil, and fenarimol in California grapevines. Plant Dis. 80:902-909.

10. Köller, W., and Wubben, J. P. 1989. Variable resistance factors of fungicides acting as sterol demethylation inhibitors. Pestic. Sci. 26:133-145.

11. Miller, T. C., and Gubler, W. D. 2004. Sensitivity of California isolates of Uncinula necator to trifloxystrobin and spiroxamine, and update on triadimefon sensitivity. Plant Dis. 88:1205-1212.

12. National Agricultural Statistics Service 1992-2006, Agricultural Chemical Usage-Fruits. http://usda.mannlib.cornell.edu/MannUsda/viewDocument Info.do?documentID=1567.

13. Northover, J., and Homeyer, G. A. 2001. Detection and management of myclobutanil-resistant grapevine powdery mildew (Uncinula necator) in Ontario. Can. J. Plant Pathol. 23:337-345.

14. Pearson, R. C., and Gadoury, D. M. 1992. Powdery mildew of grape. Pages 129-146 in: Plant Diseases of International Importance: Vol. 3. Diseases of Fruit Crops. J. Kumar, H. S. Chaube, U. S. Singh, and A. N. Mukhopadhyay, eds. Prentice Hall, Englewood Cliff, NJ.

15. Reifschneider, F. J. B., and Boiteux, L. S. 1988. A vacuum-operated settling tower for inoculation of powdery mildew fungi. Phytopathology 78:14631465.

16. Rozen, S., and Skaletsky, H. J. 2000. Primer3 on the WWW for general users and for biologist programmers. Pages 365-386 in: Bioinformatics Methods and Protocols: Methods in Molecular Biology. S. Krawetz and S. Misener, eds. Humana Press, Totowa, NJ.

17. Steva, H., and Clerjeau, M. 1990. Cross resistance to sterol biosynthesis inhibitor fungicides in strains of Uncinula necator isolated in France and Portugal. Meded. Fac. Landbouwwet. Rijksuniv. Gent 55:983-988.

18. Wilcox, W. F., Burr, J. A., Riegel, D. G., and Wong, F. P. 2003. Practical resistance to QoI fungicides in New York populations of Uncinula necator associated with quantitative shifts in pathogen sensitivities. (Abstr.) Phytopathology 93:S90.

19. Wilcox, W. F., and Riegel, D. G. 2010. Evaluation of fungicide programs for control of grapevine powdery mildew, 2008. Plant Disease Management Reports 4:SMF045. Online publication. doi:10.1094/PDMR04.

20. Wong, F. P., and Wilcox, W. F. 2002. Sensitivity to azoxystrobin among isolates of Uncinula necator: Baseline distribution and relationship to myclobutanil sensitivity. Plant Dis. 86:394-404.

21. Ypema, H. L., Ypema, M., and Gubler, W. D. 1997. Sensitivity of Uncinula necator to benomyl, triadimefon, myclobutanil, and fenarimol in California. Plant Dis. 81:293-297. 